\title{
Topical calcineurin inhibitors in systemic lupus erythematosus
}

This article was published in the following Dove Press journal:

Therapeutics and Clinical Risk Management

5 March 2010

Number of times this article has been viewed

\section{Christos E Lampropoulos David P D'Cruz}

Lupus Research Unit, Rayne Institute, St. Thomas' Hospital, London, UK

Correspondence: David P D'Cruz, Lupus Research Unit, Rayne Institute, St. Thomas' Hospital, Lambeth Palace Road, London SEI 7EH, UK

Tel +44207 I88 3570

Fax +44 $207 \quad 1883574$

Email david.d'cruz@kcl.ac.uk
Abstract: Cutaneous lupus erythematosus (CLE) encompasses a variety of lesions that may be refractory to systemic or topical agents. Discoid lupus erythematosus (DLE) and subacute cutaneous lupus erythematosus (SCLE) are the most common lesions in clinical practice. The topical calcineurin inhibitors, tacrolimus and pimecrolimus, have been used to treat resistant cutaneous lupus since 2002 and inhibit the proliferation and activation of T-cells and suppress immune-mediated cutaneous inflammation. This article reviews the mechanism of action, efficacy, adverse effects, and the recent concern about their possible carcinogenic effect. Although the total number of patients is small and there is only one relevant randomized controlled study, the data are encouraging. Many patients, previously resistant to systemic agents or topical steroids, improved after four weeks of treatment. DLE and SCLE lesions were less responsive, reflecting the chronicity of the lesions, although more than $50 \%$ of patients still showed improvement. Topical calcineurin inhibitors may be a safe and effective alternative to topical steroids for CLE although the only approved indication is for atopic dermatitis.

Keywords: tacrolimus, pimecrolimus, cutaneous lupus erythematosus, topical calcineurin inhibitors

\section{Introduction}

Cutaneous lesions are a common and often disfiguring manifestation of autoimmune connective tissue diseases. Cutaneous lupus erythematosus (CLE) is a broad term which includes a variety of lesions which may appear without the systemic manifestations of systemic lupus erythematosus (SLE). Pure CLE is usually not life-threatening, but frequently contributes to significant clinical and psychological morbidity, especially when lesions develop on the face. By contrast, cutaneous lesions commonly develop in patients with SLE.

The most widely used classifications of CLE are those of Gillian ${ }^{1}$ and Kuhn. ${ }^{2}$ The clinical manifestations of CLE are divided into acute (ACLE), subacute (SCLE), chronic (CCLE) and intermittent (ICLE) forms. ACLE typically presents in the context of the systemic disease as a photosensitive, maculopapular rash over sun-exposed areas or as a localized malar rash. SCLE appears as annular polycyclic or psoriasiform lesions in sun-exposed areas without scarring. CCLE is further divided into discoid lupus erythematosus (DLE, scarring erythematosus macules or plaques with pigment changes localized to the upper part of the body, arms and face), lupus profundus (LEP, panniculitis) and chilblain lupus (CHLE, pernio-like skin lesions). ICLE presents as lupus tumidus (urticarial lesions in sun-exposed areas). submit your manuscript $\mid$ www.dovepress.com

Dovepress 
Administration of systemic agents such as corticosteroids, hydroxychloroquine, mepacrine, methotrexate, mycophenolate mofetil, cyclophosphamide and/or azathioprine for the underlying systemic disease leads in many cases to remission of the cutaneous lesions. The use of topical treatments such as steroids, and barrier sun protection in conjunction with systemic treatment usually provides additional benefit. Nevertheless, many patients suffer from resistant cutaneous lesions despite therapy. On the other hand, cutaneous lesions may be the only manifestation of disease such as SCLE and DLE, making it difficult to justify systemic agents, because of their side effects. A variety of systemic (dapsone, thalidomide, retinoids, IV immunoglobulins) and topical agents (intralesional steroids, retinoids) as well as laser therapy, phototherapy, photopheresis, and cryotherapy have been used for resistant cutaneous lesions. ${ }^{3}$ There is a need therefore for alternative therapies.

The literature was systematically reviewed for all the articles involving topical calcineurin inhibitors by using the Medline search database. Search terms included tacrolimus, pimecrolimus, cutaneous lupus erythematosus and topical calcineurin inhibitors. All the publications involving clinical trials (prospective, retrospective, or case-controlled studies) in lupus patients were included in this review as well as many publications relevant to the pathophysiology of pimecrolimus and tacrolimus and experience in other diseases.

\section{Topical calcineurin inhibitors}

Tacrolimus (FK506) is a macrolide immunomodulator which was isolated in 1984 from the fungus Streptomyces Tsukubaensis, which was found near Tsukuba mountain in Ibraki, Japan. The word tacrolimus is derived from Tsukuba, macrolide and immunosuppression. Pimecrolimus (SDZ ASM 981) is a synthetic product of ascomycin which is a product of Streptomyces hygroscopicus.

These agents bind to the cytoplasmic protein macrophilin12 , forming a complex that blocks the serine-threonine phosphatase calcineurin. ${ }^{4}$ Calcineurin is a protein that activates, by dephosphorylation, the cytoplasmic subunit of nuclear factor of activated T-cells (NF-AT), which enters the nucleus and forms a complex with the nuclear subunit promoting the production of many cytokines such as interleukin-2 (IL-2), IL-3, IL-4, IL-5, interferon- $\gamma$, and tumor necrosis factor- $\alpha$ (TNF- $\alpha){ }^{5-7}$

Calcineurin inhibitors inhibit T-cell activation. They also inhibit mast cell degranulation and release of inflammatory mediators such as histamine, tryptase, and cytokines. ${ }^{8}$ Pimecrolimus, but not tacrolimus, has no effects on dendritic cells and does not affect maturation of Langerhans cells in infants. ${ }^{9}$ Neither agent affects endothelial cells or fibroblasts, so do not cause skin atrophy or telangiectasis. Their propensity to pass through the skin is lower than that of steroids, avoiding any systemic side effects from their absorption. ${ }^{10}$ Pimecrolimus is 20 times more lipophilic than tacrolimus, with a higher affinity for skin and lower permeation even in severely inflamed skin. ${ }^{11}$ On the other hand, tacrolimus has a stronger immunosuppressant capacity than pimecrolimus. ${ }^{12}$

\section{Treatment indications}

In 1989, oral tacrolimus was first used in preventing graft rejection after solid organ transplantation (liver, kidneys, lungs). ${ }^{13}$ In November 2000, tacrolimus ointment was approved by the US FDA Dermatologic Committee for the treatment of atopic dermatitis in children and adults and this remains the only approved indication. ${ }^{14,15}$

Since then, topical calcineurin inhibitors have been used off-label in many resistant cutaneous lesions in other diseases such as psoriasis, ${ }^{16}$ localized scleroderma, ${ }^{17}$ chronic actinic dermatitis, ${ }^{18}$ pyoderma gangrenosum, ${ }^{19}$ Behçet's disease ${ }^{20}$ lichen planus, ${ }^{21}$ rheumatoid ulcers, ${ }^{22}$ steroid-induced rosacea, ${ }^{23}$ vitiligo, ${ }^{24}$ dermatomyositis, ${ }^{25}$ hand eczema, ${ }^{26}$ asteatotic eczema, ${ }^{27}$ autoimmune bullous dermatosis, ${ }^{28}$ seborrheic dermatitis, ${ }^{29}$ allergic contact dermatitis, ${ }^{30}$ and graft-versus-host disease. ${ }^{31}$ The commercially available forms are Protopic ${ }^{\circledR}$ or Prograf ${ }^{\circledR} 0.03 \%$ and $0.1 \%$ ointment (tacrolimus) and Elidel ${ }^{\circledR} 1 \%$ cream (pimecrolimus).

\section{Safety}

The topical calcineurin inhibitors appear to be safe for use in chronic inflammatory skin diseases. ${ }^{32}$ Side effects are usually mild, and include irritation, pruritus, burning sensation, or increased erythema. These adverse reactions are usually transient and subside with continuation oftreatment. Low penetration of the inflamed skin reduces the risks of any systemic side effects.

These agents seem to be a safer alternative to potent topical steroids, which usually are effective, cheap and fast-acting but their chronic use results in skin atrophy, teleangiectasiae, dermatitis, and pustules. Calcineurin inhibitors can be used safely over sensitive areas like the face, mucous membranes, and genitalia ${ }^{33}$ where the skin is thin, or during infancy and early childhood. They are not systemically absorbed even when large areas of skin are affected. They are highly effective even as monotherapy and they result in rapid and sustained improvement. There have been no reports of any statistically significant incidence of local infections (bacterial, viral, or fungal) during their use, ${ }^{34}$ although there may be a slightly increased risk for local Varicella zoster virus, Herpes simplex virus, eczema herpeticum, impetigo, and 
molluscum contagiosum. ${ }^{35}$ Clearly however, they should not be used in obviously infected skin lesions.

Although generally safe, in March 2005 the Food and Drug Administration (FDA) informed health care professionals and patients about a potential risk of cancer from the use of tacrolimus which was based on animal studies and case reports. ${ }^{36}$ The first report was that of a squamous cell cancer of the penis after use of tacrolimus. ${ }^{37}$ Since then, more than 19 cases of cancer were reported in association with tacrolimus use. Half of them involved lymphomas and the rest were skin tumors at the site of application (squamous cell carcinoma, sarcoma, melanoma). ${ }^{38,39}$ In animal models it was found that tacrolimus reduces the $\mathrm{CD} 4 / \mathrm{CD} 8$ ratio in lymph nodes and that its concentration in the draining lymph nodes was as high as after oral use. ${ }^{40}$ Tacrolimus was also found to inhibit apoptosis in nonlymphoid cells and to affect proteins that participate in the cancer signaling pathways (Erk activation resulting in cell proliferation and p53 inhibition resulting in reduced apoptosis). ${ }^{41}$

On the other hand, many reviews and publications failed to connect topical calcineurin inhibitors with an increased risk of cancer ${ }^{42}$ in adults and children. ${ }^{43,44}$ There was no evidence of systemic immunosuppression among infants treated intermittently with $1 \%$ pimecrolimus for up to two years, and all demonstrated a normal immune response to vaccinations without increased systemic or skin infections. ${ }^{45,46}$ The analysis of data from clinical studies with more than five million patients treated with pimecrolimus cream since December 2001 failed to show any increased risk of cancer. ${ }^{47}$

A recent study showed that topical calcineurin inhibitors were associated with a slightly increased risk of lymphoma compared with the general population, but the same risk was also noticed in users of topical steroids, suggesting that all topical treatments may increase lymphoma risk. ${ }^{48}$ Another study found an association between lymphoma (especially of the skin) and use of topical steroids but not with calcineurin inhibitors and that the risk depended on steroid potency and duration of exposure. ${ }^{49}$

\section{Topical calcineurin inhibitors and cutaneous lupus erythematosus}

Many case reports and a few prospective trials have been published since 2002 when lupus skin lesions were first treated with topical calcineurin inhibitors (see Table 1). The first report was by Yoshimasu et $\mathrm{a}^{50}$ who used tacrolimus ointment $0.1 \%$ once a day for four weeks in three SLE and

Table I Topical calcineurin inhibitors in cutaneous lupus erythematosus

\begin{tabular}{|c|c|c|c|}
\hline References & Patients & Treatment & Successful treatment \\
\hline$\overline{48}$ & 3 SLE, 4 DLE & tacrolimus $0.1 \%$ & 3 SLE, I DLE \\
\hline 49 & 2 DLE & $\begin{array}{l}\text { tacrolimus } 0.03 \% \text { in } \\
\text { clobetasol propionate } 0.05 \%\end{array}$ & 2 DLE \\
\hline 50 & I DLE & pimecrolimus I\% & I DLE \\
\hline 51 & I LET & tacrolimus $0.1 \%$ & I LET \\
\hline 52 & I SLE, 2 SCLE & tacrolimus $0.1 \%$ & I SLE, 2 SCLE \\
\hline 53 & 3 SLE & tacrolimus $0.1 \%$ & 3 SLE \\
\hline 54 & I SCLE & tacrolimus $0.1 \%$ & I SCLE \\
\hline 55 & I DLE & tacrolimus $0.1 \%$ & I DLE \\
\hline 56 & 5 DLE, 4 SCLE, 2 SLE & tacrolimus $0.1 \%$ & 3 DLE, 2 SCLE, 2 SLE \\
\hline 57 & 4 DLE, 3 SLE, 2 SCLE, 2 LET & pimecrolimus I\% & 4 DLE, 3 SLE, 2 SCLE, 2 LET \\
\hline 58 & IO DLE & pimecrolimus I\% & IO DLE \\
\hline 60 & 5 DLE & tacrolimus $0.1 \%$ & 5 DLE \\
\hline 61 & I SCLE & tacrolimus $0.1 \%$ & I SCLE \\
\hline 62 & I SCLE & tacrolimus $0.1 \%$ & I SCLE \\
\hline 63 & 4 DLE & tacrolimus $0.1 \%$ & 4 DLE \\
\hline 64 & 2 SLE, 2 DLE & tacrolimus $0,1 \%$ & I SLE, I DLE \\
\hline 65 & I SLE/lichen planus & tacrolimus $0.1 \%$ & I SLE/lichen planus \\
\hline 66 & I3 SLE, 4 DLE, I SCLE & $\begin{array}{l}\text { tacrolimus I } \% \text { vs } \\
\text { clobetasol propionate } 0.05 \%\end{array}$ & $\begin{array}{l}\text { I } 3 \text { SLE, } 4 \text { DLE, I SCLE, } \\
\text { fewer side effects }\end{array}$ \\
\hline 67 & $18 \mathrm{CLE}$ & $\begin{array}{l}\text { tacrolimus } 0.3 \% \text { plus } \\
\text { clobetasol vs monotherapy }\end{array}$ & Better results with combination \\
\hline
\end{tabular}

Abbreviations: CLE, cutaneous lupus erythematosus; DLE, discoid lupus erythematosus; SCLE, subacute cutaneous lupus erythematosus; SLE, systemic lupus erythematosus; LET, lupus tumidus. 
four DLE patients with facial rash, and four further patients with dermatomyositis. Improvement was noticed in all SLE patients but only in one with discoid lesions. Walker et $\mathrm{al}^{51}$ reported two patients with discoid lupus who showed significant improvement with tacrolimus ointment $0.03 \%$ in $0.05 \%$ clobetasol propionate cream while Zabawski ${ }^{52}$ reported one patient with discoid lupus treated successfully with pimecrolimus cream $1 \%$.

Tacrolimus was also effective in the treatment of one patient with lupus tumidus. ${ }^{53}$ Böhm et al ${ }^{54}$ successfully treated three patients (one with SLE and two with SCLE) with tacrolimus and Kanekura et $\mathrm{al}^{55}$ had the same results in three patients with SLE and facial skin lesions.

In 2004, Drüke et $\mathrm{al}^{56}$ and de la Rosa Carrillo et $\mathrm{al}^{57}$ treated one patient with SCLE and one patient with discoid lupus with tacrolimus. Lampropoulos et $\mathrm{al}^{58}$ published an open-label study of 11 patients comprising five with discoid lupus, four with SCLE and two with SLE. Tacrolimus ointment was applied twice daily for six weeks with a good response in both patients with SLE, two of four patients with SCLE (see Figure 1) and two patients with discoid lupus, while one patient with DLE had a partial response. A couple of months later an open uncontrolled clinical trial was published by Kreuter et al $^{59}$ who used pimecrolimus $1 \%$ cream in 11 patients with different forms of lupus erythematosus comprising four with DLE, three with SLE, two with SCLE, and two with lupus tumidus. Pimecrolimus cream was applied twice daily for three weeks under semiocclusive conditions (overnight occlusion with hydrocolloid dressings) with significant improvement in all patients $(57 \%$ improvement on a clinical severity score).

In 2005, Tlacuilo-Parra et $\mathrm{al}^{60}$ reported 10 patients with discoid lupus treated successfully with pimecrolimus for eight weeks. The overall improvement on a clinical severity score was $52 \%$. Three patients showed a reduction of more than
$70 \%$, four patients $50 \%-70 \%$, and three patients $30 \%-50 \%$. All patients had a skin biopsy before and after treatment which showed a significant reduction in the density of the dermal lymphocytic infiltrate. A quality of life index was also used (Skindex-29), ${ }^{61}$ with a mean improvement of $46 \%$. In the same year Heffernan et $\mathrm{al}^{62}$ reported five patients with discoid lupus erythematosus who showed improvement of their rash after 12 weeks of tacrolimus ointment. Meller et $\mathrm{al}^{63}$ described one patient with SCLE and Cassis et $\mathrm{al}^{64}$ a further patient with SCLE attributable to monocyclic antidepressant therapy who were treated successfully with tacrolimus.

Three publications concerning the use of calcineurin inhibitors and cutaneous lupus erythematosus were published in 2006. Sugano et $\mathrm{al}^{65}$ successfully treated four patients with discoid lupus using tacrolimus ointment for 4-8 weeks while von Pelchrzim et $\mathrm{al}^{66}$ had $50 \%$ success (one of two patients with SLE and one of two patients with DLE). Nagao et al ${ }^{67}$ reported a patient with cutaneous lupus overlapping with lichen planus who was treated effectively with tacrolimus.

Tzung et $\mathrm{al}^{68}$ published the first randomized, double-blind, controlled study in 2007. Eighteen patients with facial rashes participated, of whom 13 had SLE, four had DLE and one had SCLE. Tacrolimus ointment was applied twice daily on one side of the face and clobetasol propionate $0.05 \%$ ointment on the other side. A partial response was noticed in all patients without significant differences between the two creams, but 11 patients developed teleangiectasiae on the clobetasol side during the first three weeks, indicating better tolerability and safety of tacrolimus compared with topical steroids.

A retrospective study was published in 2009 by Madan et al. ${ }^{69}$ A specially formulated preparation of tacrolimus $0.3 \%$ in clobetasol propionate $0.05 \%$ ointment was compared with either $0.1 \%$ tacrolimus or clobetasol propionate $0.05 \%$ as monotherapy in 18 patients with cutaneous lupus



A

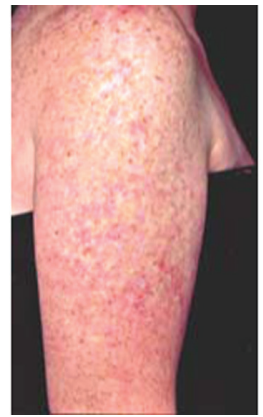

B

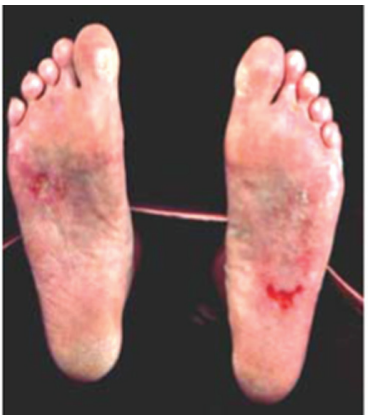

C

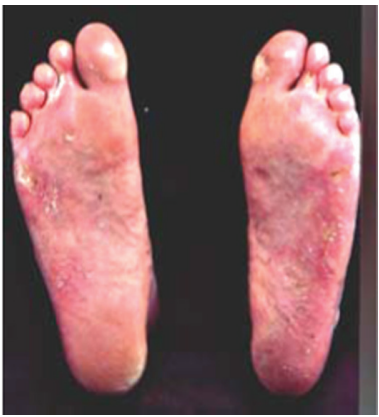

D

Figure I Two patients with SCLE lesions on upper right limb and SCLE lesions on soles, respectively, before (A, C) and after (B, D) treatment with tacrolimus ointment. Copyright (C) 2004. Reprinted with permission from Lampropoulos CE, Sangle S, Harrison P, Hughes GR, D'Cruz DP. Topical tacrolimus therapy of resistant cutaneous lesions in lupus erythematosus: A possible alternative. Rheumatology (Oxford). 2004;43:1383-1 385.

Abbreviation: SCLE, subacute cutaneous lupus erythematosus. 
erythematosus, which seemed to be more effective. This is in accordance with experimental evidence that combination of corticosteroids with calcineurin inhibitors can achieve superior therapeutic efficacy and stronger inhibition of T-cell proliferation compared with monotherapy. ${ }^{70}$

\section{Discussion}

Cutaneous lesions in lupus erythematosus may prove very resistant to classical systemic and topical agents. These lesions usually appear in visible areas resulting in significant psychological effects. Therapy is often unsatisfactory because of recalcitrant disease or serious side effects from corticosteroids.

Over the last two decades, tacrolimus and the newer calcineurin inhibitor pimecrolimus have emerged as effective immunosuppressive and anti-inflammatory agents. The experience in atopic dermatitis showed that they are very effective and safe, especially in children and for facial lesions where only weak topical steroids can be used. These ointments are expensive, but a cost-effectiveness analysis showed that in the long term the cost is similar for tacrolimus and high-potency corticosteroids. ${ }^{71}$ They are not systemically absorbed, even when large areas of skin are affected, and their adverse reactions usually subside with continuation of treatment. Their use must be combined with sun protection because most of the cutaneous lesions in lupus are photosensitive.

The usual effective treatment is application of the cream twice daily for at least four weeks, during which time improvement of symptoms is expected. Skin lesions in SLE can improve significantly in most patients, but this is less likely in patients with discoid lupus or SCLE. The response to treatment is partial in these particular types of cutaneous lupus and prolonged therapy may be needed, reflecting the chronicity and unresponsiveness of these lesions. ${ }^{72}$ Nevertheless, $50 \%-60 \%$ of patients report a partial or good response, an encouraging result if we consider that these cutaneous lesions are usually resistant to systemic or other topical agents. Recent studies have shown that combination of calcineurin inhibitors with steroids is more effective than monotherapy, suggesting that this should be considered for very resistant lesions.

Most of the publications are case reports with small numbers of patients. The only randomized, double-blind study showed calcineurin inhibitors and steroids had similar efficacy but without serious side effects, reflecting the necessity for more prospective trials with larger numbers of patients. The warning issued by the FDA regarding the possible low risk of cancer should be considered by the prescribing physician, especially as these agents remain offlabel for use in lupus. A further consideration is the increased risk of lymphoma that is associated with having SLE, ${ }^{73}$ and so treatment should be limited to short periods of time. In conclusion, the data in the literature taken together suggest that topical calcineurin inhibitors can be considered to be a relatively safe and attractive alternative treatment for resistant cutaneous lesions in lupus erythematosus.

\section{Disclosures}

The authors report no conflict of interest in this work.

\section{References}

1. Gillian JN, Sontheimer RD. Distinctive cutaneous subsets in the spectrum of lupus erythematosus. J Am Acad Dermatol. 1981;4:471-475.

2. Kuhn A, Ruzicka T. Classification of cutaneous lupus erythematosus. In: Kuhn A, Lehmann P, Ruzicka T, editors. Cutaneous lupus erythematosus. Heidelberg, Germany: Springer; 2005.

3. Ting WW, Sontheimer RD. Local therapy for cutaneous and systemic lupus erythematosus: Practical and theoretical considerations. Lupus. 2001;10:171-184.

4. Sárdy M, Ruzicka T, Kuhn A. Topical calcineurin inhibitors in cutaneous lupus erythematosus. Arch Dermatol Res. 2009;301:93-98.

5. Homey B, Assmann T, Vohr HW, et al. Topical FK506 suppresses cytokine and costimulatory molecule expression in epidermal and local draining lymph node cells during primary skin immune responses. J Immunol. 1998;160:5331-5340.

6. Gisondi P, Ellis CN, Girolomoni G. Pimecrolimus in dermatology: Atopic dermatitis and beyond. Int J Clin Pract. 2005;59:969-974.

7. Marsland AM, Griffiths CE. The macrolide immunosuppressants in dermatology: Mechanisms of action. Eur J Dermatol. 2002;12: 618-622.

8. Grassberger M, Steinhoff M, Schneider D, Luger TA. Pimecrolimus an anti-inflammatory drug targeting the skin. Exp Dermatol. 2004;13:721-730.

9. Meindl S, Vaculik C, Meingassner JG, et al. Differential effects of corticosteroids and pimecrolimus on the developing skin immune system in humans and mice. J Invest Dermatol. 2009;129:2184-2192.

10. Billich A, Aschauer H, Aszodi A, Stuetz A. Percutaneous absorption of drugs used in atopic eczema: Pimecrolimus permeates less through skin than corticosteroids and tacrolimus. Int J Pharm. 2004;269: 29-35.

11. Weiss HM, Fresneau M, Moenius T, Stuetz A, Billich A. Binding of pimecrolimus and tacrolimus to skin and plasma proteins: Implications for systemic exposure after topical application. Drug Metab Dispos. 2008;36:1812-1818.

12. Wolff K, Stuetz A. Pimecrolimus for the treatment of inflammatory skin disease. Expert Opin Pharmacother. 2004;5:643-655.

13. Starzl TE, Todo S, Fung J. FK506 for liver, kidney and pancreas transplantation. Lancet. 1989;2:1000-1004.

14. US FDA Advisory Committee recommends approval for Tacrolimus ointment. Skin Ther Lett. 2000;6:5.

15. Nakagawa H, Etoh T, Ishibashi Y, et al. Tacrolimus ointment for atopic dermatitis. Lancet. 1994;344:883.

16. Yamamoto T, Nishioka K. Topical tacrolimus: An effective therapy for facial psoriasis. Eur J Dermatol. 2003;13:471-473.

17. Mancuso G, Berdondini RM. Topical tacrolimus in the treatment of localized scleroderma. Eur J Dermatol. 2003;13:590-592.

18. Evans AV, Palmer RA, Hawk JK. Erythrodermic chronic actinic dermatitis responding only to topical tacrolimus. Photodermatol Photoimmunol Photomed. 2004;20:59-61. 
19. Petering H, Kiehl P, Breuer C, Kapp A, Werfel T. Pyoderma gangrenosum: Successful topical therapy with tacrolimus (FK506). Hautarzt. 2001:52:47-50.

20. Sakane T, Mochizuki M, Inuba G, Masuda K. A phase II study of FK506 (tacrolimus) on refractory uveitis associated with Behçet's disease and allied conditions. Ryumachi. 1995;35:802-813.

21. Volz T, Caroli U, Lüdtke H, et al. Pimecrolimus cream $1 \%$ in erosive oral lichen planus - a prospective randomized double-blind vehiclecontrolled study. Br J Dermatol. 2008;159:936-941.

22. Schuppe H, Richter-Hintz D, Stierle HE, Homey B, Ruzicka T, Lehmann P. Topical tacrolimus for recalcitrant leg ulcer in rheumatoid arthritis. Rheumatology. 2000;39:105-106.

23. Goldman D. Tacrolimus ointment for the treatment of steroid-induced rosacea: A preliminary report. J Am Acad Dermatol. 2001;44: 995-998.

24. Gawrodger DJ, Ormerod AD, Shaw L, et al. Guideline for the diagnosis and management of vitiligo. Br J Dermatol. 2008;159:1051-1076.

25. Lampropoulos CE, D'Cruz DP. Topical tacrolimus treatment in a patient with dermatomyositis. Ann Rheum Dis. 2005;64:1376-1377.

26. Robertson L. New and existing therapeutic options for hand eczema. Skin Therapy Lett. 2009;14:1-5.

27. Wollina $U$. The role of topical calcineurin inhibitors for skin diseases other than atopic dermatitis. Am J Clin Dermatol. 2007;8:157-173.

28. Luger T, Paul C. Potential new indications of topical calcineurin inhibitors. Dermatology. 2007;215 Suppl 1:S45-S54.

29. Cook BA, Warshaw EM. Role of topical calcineurin inhibitors in the treatment of seborrheic dermatitis: A review of pathophysiology, safety and efficacy. Am J Clin Dermatol. 2009;10:103-118.

30. Rallis E, Korfitis C, Gregoriou S, Rigopoulos D. Assigning new roles to topical tacrolimus. Expert Opin Investig Drugs. 2007;16:1267-1276.

31. Wolff D, Steiner B, Hildebrandt G, Edinger M, Holler E. Pharmaceutical and cellular strategies in prophylaxis and treatment of graft-versus-host disease. Curr Pharm Res. 2009;15:1974-1997.

32. Woo DK, James WD. Topical tacrolimus: A review of its uses in dermatology. Dermatitis. 2005;16:6-21.

33. Draelos ZD. Use of topical corticosteroids and topical calcineurin inhibitors for the treatment of atopic dermatitis in thin and sensitive skin areas. Curr Med Res Opin. 2008;24:985-994.

34. Gupta AK, Chow M. Pimecrolimus: A review. J Eur Acad Dermatol Venereol. 2003;17:493-503.

35. Langley RG, Luger TA, Cork MJ, Schneider D, Paul C. An update on the safety and tolerability of pimecrolimus cream 1\%: Evidence from clinical trials and post-marketing surveillance. Dermatology. 2007; 215 Suppl 1:S27-S44

36. US Food and Drug Administration. FDA Public Health Advisory: Elidel (pimecrolimus) cream and Protopic (tacrolimus) ointment. Rockville, MD: US Food and Drug Administration; 2005.

37. Langeland T, Engh V. Topical use of tacrolimus and squamous cell carcinoma on the penis. Br J Dermatol. 2005;152:183-185

38. Becker JC, Houben R, Velter CS, Bröcker EB. The carcinogenic potential of tacrolimus ointment beyond immune suppression: A hypothesis creating case report. BMC Cancer. 2006;6:7.

39. Wooltorton E. Eczema drugs tacrolimus (Protopic) and pimecrolimus (Elidel): Cancer concerns. CMAJ. 2005;172:1179-1180.

40. Niwa Y, Nasr I. Are we starting to induce skin cancer in order to avoid topical steroids? J Eur Acad Dermatol Venereol. 2005;19:387-389.

41. Gomez-Lechon MJ, Serralta A, Donato MT, et al. The immunosuppressant drug FK506 prevents Fas-induced apoptosis in human hepatocytes. Biochem Pharmacol. 2004;68:2427-2433.

42. Rustin MH. The safety of tacrolimus ointment for the treatment of atopic dermatitis: A review. Br J Dermatol. 2007;157:861-873.

43. Paul C, Cork M, Rossi AB, Papp KA, Barbier N, de Prost Y. Safety and tolerability of $1 \%$ pimecrolimus cream among infants: Experience with 1133 patients treated up to 2 years. Pediatrics. 2006;117:118-128.

44. Ring J, Barker J, Behrendt H, et al. Review of the potential photococarcinogenicity of topical calcineurin inhibitors: Position statement of the European Dermatology Forum. J Eur Acad Dermatol Venereol. 2005; 19:663-671.
45. Papp KA, Werfel T, Fölster-Holst R, et al. Long-term control of atopic dermatitis with pimecrolimus cream $1 \%$ in infants and young children: A two-year study. J Am Acad Dermatol. 2005;52:240-246.

46. Papp KA, Breuer K, Meurer M, et al. Long-term treatment of atopic dermatitis with pimecrolimus cream $1 \%$ in infants does not interfere with the development of protective antibodies after vaccination. $J \mathrm{Am}$ Acad Dermatol. 2005;52:247-253.

47. US Food and Drug Administration. Novartis Elidel (pimecrolimus) cream 1\% briefing document. Rockville, MD: US Food and Drug Administration; 2005.

48. Schneeweiss S, Doherty M, Zhu S, et al. Topical treatments with pimecrolimus, tacrolimus and medium-to high-potency corticosteroids and risk of lymphoma. Dermatology. 2009;219:7-21.

49. Arellano FM, Arana A, Wentworth CE, Fernández-Vidaurre C, Schlienger RG, Conde E. Lymphoma among patients with atopic dermatitis and/or treated with topical immunosuppressants in the United Kingdom. J Allergy Clin Immunol. 2009;123:1111-1116.

50. Yoshimasu T, Ohtani T, Sakamoto T, Oshima A, Furukawa F. Topical FK506 (tacrolimus) therapy for facial erythematous lesions of cutaneous lupus erythematosus and dermatomyositis. Eur J Dermatol. 2002;12:50-52.

51. Walker SL, Kirby B, Chalmers RJ. The effect of topical tacrolimus on severe recalcitrant chronic discoid lupus erythematosus. Br J Dermatol. 2002;147:405-406.

52. Zabawski E. Treatment of cutaneous lupus with Elidel. Dermatol Online J. 2002;8:25.

53. Bacman D, Tanbajewa A, Megahed M, Ruzicka T, Kuhn A. Topical treatment with tacrolimus in lupus erythematosus tumidus. Hautarzt. 2003;54:977-979.

54. Böhm M, Gaubitz M, Luger TA, Metze D, Bousmann G. Topical tacrolimus as a therapeutic adjunct in patients with cutaneous lupus erythematosus. A report of three cases. Dermatology. 2003;207: 381-385.

55. Kanekura T, Yoshii N, Terasaki K, Miyoshi H, Kanzaki T. Efficacy of topical tacrolimus for treating the malar rash of systemic lupus erythematosus. Br J Dermatol. 2003;148:353-356.

56. Drüke A, Gambichler T, Altmeyer P, Dreitag M, Kreuter A. 0.1\% Tacrolimus ointment in a patient with subacute cutaneous lupus erythematosus. J Dermatolog Treat. 2004;15:63-64.

57. De la Rosa Carrillo D, Christensen OB. Treatment of chronic discoid lupus erythematosus with topical tacrolimus. Acta Derm Venereol. 2004;84:233-234.

58. Lampropoulos CE, Sangle S, Harrison P, Hughes GR, D'Cruz DP. Topical tacrolimus therapy of resistant cutaneous lesions in lupus erythematosus: A possible alternative. Rheumatology (Oxford). 2004;43:1383-1385.

59. Kreuter A, Gambichler T, Breuckmann F, et al. Pimecrolimus 1\% cream for cutaneous lupus erythematosus. J Am Acad Dermatol. 2004;51:407-410.

60. Tlacuilo-Parra A, Guevara-Gutiérrez E, Gutiérrez-Murillo F, et al. Pimecrolimus $1 \%$ cream for the treatment of discoid lupus erythematosus. Rheumatology (Oxford). 2005;44:1564-1568.

61. Jones-Caballero M, Pẽnas PF, Garcia-Diez A, Badia X, Chren MM. The Spanish version of skindex-29. Int J Dermatol. 2000;39:907-912.

62. Heffernan MP, Nelson MM, Smith DI, Chung JH. 1\% tacrolimus ointment in the treatment of discoid lupus erythematosus. Arch Dermatol. 2005;141:1170-1171.

63. Meller S, Bruch-Gerharz D, Ruzicka T, Homey B. Topical treatment of subacute-cutaneous lupus erythematosus with tacrolimus. Hautarzt. 2005;56:368-369.

64. Cassis TB, Callen JP. Bupropion-induced subacute cutaneous lupus erythematosus. Australas J Dermatol. 2005;46:266-269.

65. Sugano M, Shintani Y, Kobayashi K, Sakakibura N, Isomura I, Morita A. Successful treatment with topical tacrolimus in four cases of discoid lupus erythematosus. J Dermatol. 2006;33:887-891.

66. Von Pelchrzim R, Schmook T, Friedrich M, Worm M. Efficacy of topical tacrolimus in the treatment of various cutaneous manifestations of lupus erythematosus. Int J Dermatol. 2006;45:84-85. 
67. Nagao K, Chen KR. A case of lupus erythematosus/lichen planus overlap syndrome. J Dermatol. 2006;33:187-190.

68. Tzung TY, Liu YS, Chang HW. Tacrolimus vs clobetasol propionate in the treatment of facial cutaneous lupus erythematosus: A randomized, double-blind, bilateral comparison study. Br J Dermatol. 2007;156: 191-192.

69. Madan V, August PJ, Chalmers RJ. Efficacy of topical tacrolimus $0.3 \%$ in clobetasol propionate $0.05 \%$ ointment in therapy-resistant cutaneous lupus erythematosus: A cohort study. Clin Exp Dermatol. 2009;34:705-708.

70. Winiski A, Wang S, Schwendinger B, Stuetz A. Inhibition of T-cell activation in vitro in human peripheral blood mononuclear cell by pimecrolimus and glucocorticosteroids and combinations thereof. Exp Dermatol. 2007;16:699-704.

71. Ellis CN, Drake LA, Prendergast MM, et al. Cost-effectiveness analysis of tacrolimus ointment versus high-potency topical corticosteroids in adults with moderate to severe atopic dermatitis. J Am Acad Dermatol. 2003;48:553-563.

72. Wollina U, Hansel G. The use of topical calcineurin inhibitors in lupus erythematosus: An overview. J Eur Acad Dermatol Venereol. 2008;22:1-6.

73. Bernatsky S, Ramsey-Goldman R, Isenberg D, et al. Hodgkin's lymphoma in systemic lupus erythematosus. Rheumatology (Oxford). 2007;46:830-832.

\section{Publish your work in this journal}

Therapeutics and Clinical Risk Management is an international, peerreviewed journal of clinical therapeutics and risk management, focusing on concise rapid reporting of clinical studies in all therapeutic areas, outcomes, safety, and programs for the effective, safe, and sustained use of medicines. This journal is indexed on PubMed Central, CAS,
EMBase, Scopus and the Elsevier Bibliographic databases. The manuscript management system is completely online and includes a very quick and fair peer-review system, which is all easy to use. Visit http://www.dovepress.com/testimonials.php to read real quotes from published authors.

Submit your manuscript here: http://www.dovepress.com/therapeutics-and-clinical-risk-management-journal 